\title{
Letters
}

All letters are subject to editing and may be shortened. Letters should be sent to the BJGP office

by e-mail in the first instance, addressed to journal(arcgp.org.uk (please include your postal address).

We regret that we cannot notify authors regarding publication. Letters not published in the Journal will be

posted online on our Discussion Forum. For instructions please visit: http://www.rcgp.org.uk/bjgp-discuss

\section{Obesity and chronic disease in younger people}

In your editorial on obesity, ${ }^{1}$ Yates et al talk in apocalyptic terms about the rise in its prevalence. Their description of its 'devastating consequences' is amplified to an impressive degree by the repeated use of figures referring to relative rather than absolute risk. They propose an 'urgent need for high quality research' and go on to comment approvingly on the paper from the Bristol team, ${ }^{2}$ concluding that it provides evidence that primary care can be used to engage effectively with, and manage, childhood obesity'.

To be honest, I'm not that good at analysing research papers but I felt it would be worthwhile seeing whether the paper delivered on this promise. Unless I am missing something, the main results I can see from this paper are as follows:

1. Of 152 eligible patients at the start of the trial, only 39 of them (25\%) made it through to the end of the 12-month intervention period.

2. Reductions in body mass index (BMI) seen in those who did last the course lin both the primary and secondary care groups) were modest to say the least and the authors comment that the mean change in BMI 'is too small to be certain of an improvement in metabolic health'.

3. There is no follow up beyond the 12month trial period to see if there is any sustained reduction in BMI.

A more realistic conclusion, therefore, is that this model of an obesity clinic is equally ineffective in primary and secondary care. Something perhaps to bear in mind before we rush to provide such services as part of the 're-focusing of healthcare priorities' that your editorial recommends.

Roger Tisi,

GP, Audley Mills Surgery, Rayleigh, Essex, SS6 7JF. E-mail: rbtisiagooglemail.com

\section{REFERENCES}

1. Yates T, Davies MJ, Khunti K. Obesity and chronic disease in younger people: an unfolding crisis. $\mathrm{Br}$ J Gen Pract 2012; 62(594): 4-5.

2. Banks J, Sharp DJ, Hunt LP, Shield JPH. Evaluating the transferability of a hospital-based childhood obesity clinic to primary care. $\mathrm{Br} J \mathrm{Gen}$ Pract 2012; DOI: 10.3399/bjgp12X616319.

DOI: 10.3399/bjgp12X629973

\section{Authors' response}

Thank you for inviting us to reply to the letter from $\mathrm{Dr}$ Tisi who is concerned that our conclusions are not justified by our results. Taking the points he makes in turn:

1. There were not 152 eligible patients: 152 patients were referred by their GP for specialist obesity support. These children were screened for eligibility and 31 were not deemed suitable for the trial because of obesity related comorbidities. This left a further 45 who declined to participate in the trial for various reasons. These 76 patients did not provide trial data and will have received treatment in secondary care in the usual way. It is therefore erroneous to suggest that only 39 of 152 people made it through to the end of the trial. As we make clear in our consort diagram, 39 of the 76 who were randomised completed treatment but 52 provided outcome data and were included in an intention to treat analysis.

2. We have been explicit in our acknowledgement of the modest improvement in body mass index (BMI) standard deviation score (SDS) but as we point out this is still better than described in the recent Cochrane Review. However, the main aim of the trial was to establish the feasibility of running a fully powered trial in primary care and to this end we looked at a range of measures including: whether patients referred for obesity support were clinically suitable for primary care $(121,80 \%$ suitable); the willingness of families to be randomised to primary care $145,30 \%$ declined trial participation); and the degree to which families randomised to primary care engaged with the service (measured with the main clinical outcome of BMI SDS change, patient satisfaction, and adherence rates, all of which are detailed in the article and comparable between the trial arms)

3. We recognise that in a full trial a longerterm outcome measure is essential but in a feasibility study such as this there were insufficient resources available and longterm efficacy was not an objective. However, this does not undermine the rationale for the study which was to assess the feasibility of running a specialist obesity service in primary care in order to proceed to a fully powered trial. Once such trials have been conducted and are open to scrutiny, we should be better placed to assess the value of realigning healthcare resources.

We hope that he will agree that our findings justify further research to develop interventions in the primary care setting that may assist families needing help with managing childhood obesity.

\section{Deborah Sharp,}

Professor of Primary Health Care, University of Bristol, Academic Unit of Primary Health Care, School of Social and Community Medicine, Canynge Hall, 39 Whatley Road, Bristol, BS8 2PS.

E-mail: Debbie.Sharpabristol.ac.uk

Jonathan Banks,

University of Bristol, Academic Unit of Primary Health Care, School of Social and Community Medicine, Bristol.

Linda Hunt,

University of Bristol, School of Clinical Sciences, Bristol Royal Hospital for Children, Bristol.

Julian Shield,

University of Bristol, Diabetes and Metabolic Endocrinology, Bristol Royal Hospital for Children, Bristol.

DOI: 10.3399/bjgp12X629982

\section{How to afford a just health service}

David Jewell suggests means-tested direct 
charges to patients (co-payments) as ways to afford a just health service in times of austerity. ${ }^{1}$ He had no need to search so far.

A best answer was provided 250 years ago by Adam Smith:

The subjects of every state ought to contribute towards the support of the government, as nearly as possible in proportion to their respective abilities; that is, in proportion to the revenue that they respectively enjoy under the protection of the state.'

This is what we now call income tax. It was first instituted in 1799 to pay for our wars, but only became in any way socially redistributive in Lloyd George's budget of 1909. It is, of course, means-tested. Means tests are costly to administer, and it seems pointless to do this more than once, except as an effective deterrent to a high proportion of people entitled to benefits. Of 30 countries for which The Organisation for Economic Co-operation and Development data were available in 2005, the UK ranked 11th lowest for personal income tax as a percentage of income, below every other European country except Ireland, Iceland, and Switzerland. ${ }^{3}$

Unlike any leading politician or most economists today, Adam Smith understood the function of the state as guardian of property. 'Till there be property there can be no government, the very end of which is to secure wealth, and to defend the rich from the poor', he said. ${ }^{4}$ The rich should pay more for every aspect of the state, because without it, our obscenely unequal society would fall apart.

That's the closest one can get to the truth, looking from above. It's much easier to see from below, as most still do in Wales, Scotland, and Northern Ireland. Here NHS care is seen as a progressive and civilising extension of care within families at home. Both are social functions separated so far as possible from the commodity market. They are both motivated by perceived needs rather than opportunities for profit, and are cooperative rather than competitive in nature. Neither can gain in effectiveness or efficiency by remodelling to an industrial or commercial pattern.

In dismissing co-payments as a principle conceded long ago, David Jewell reveals ignorance of history. Charges for prescriptions, spectacles, dentistry, and so on (to Chancellor Hugh Gaitskell, and a cabinet majority who agreed with him) led two ministers and one junior minister to resign from Attlee's government in 1951
(Nye Bevan, Harold Wilson, and John Freeman). They understood that the NHS was founded on solidarity. Without this it can exist only in name. People may be slow to understand this, but when they do, there will be short shrift for such casuistry.

Julian Tudor Hart,

FRCGP, FRCP, HonFFPH, Honorary

Research Fellow, University of Wales,

Swansea Medical School, Gelli Deg,

Penmaen, Swansea, SA3 $2 \mathrm{HH}$.

E-mail: juliantudorhartayahoo.co.uk

\section{REFERENCES}

1. Jewell D. How to afford a just health service. $B r J$ Gen Pract 2012; DOI: 10.3399/bjgp12X625300.

2. Smith A. An enquiry into the nature and causes of the wealth of nations (1762). Oxford: Oxford University Press, 1993.

3. OECD. Organization for economic co-operation and development 2005 data. www.oecd.org (accessed 13 Feb 2012).

4. Smith A, Cannan E. Lectures on justice, police, revenue and arms. Oxford: Kessinger Publishing, 1896: 15.

DOI: 10.3399/bjgp12X630007

\section{Is healthy eating for obese children necessarily more costly for families?}

The paper by Banks et al ' was music to my ears. As someone who has been jousting with a tendency towards obesity since my teenage years I am not only well aware of the 'healthy food costs too much' argument so beloved by patients, but the counter arguments. The one that seems to confound people most of all is 'why don't you just eat less of what you can afford to buy?' I have not yet had a sensible answer to this: generally there is a knotting of brows for a few seconds as though I were speaking in tongues, before moving on to some other issue.

It seems to me that there are two main problems to be overcome in quashing the 'healthy is expensive' argument. First the cheapness of less healthy options: the often quoted discount ready-made lasagne, for example. Second is the idea that a diet is not healthy unless it contains a liberal sprinkling of exotic fruit and veg. We are surrounded by images of blueberries with our breakfast cereal, pak choi in our '10- minute' supper, and kiwi fruit at just about any time of day. These images are propagated by magazines and diet clubs alike. Is it any wonder people think they can't afford it?

Last year one of Britain's leading supermarkets introduced menus that cost around $€ 50$ per week for a family of four. In some quarters this came under fire for such mundanities as toast for breakfast. There is nothing wrong with toast for breakfast. In many Mediterranean countries (whose diet is seen as the gold standard) it is common to skip breakfast altogether in favour of elevenses, or to take little more than bread and coffee.

By all means try to curb the purveyors of cheap, unhealthy options, but more importantly let us push a sensible, achievable alternative.

\section{Susan Martin,}

Saddleworth Medical Practice, Smithy Lane, Uppermill, Oldham, Ol3 6AH.

E-mail: susan.martin2lanhs.net

\section{REFERENCE}

1. Banks J, Williams J, Cumberlidge T, et al. Is healthy eating for obese children necessarily more costly for families? Br J Gen Pract 2012; DOI: 10.3399/bjgp12X616300.

\section{Predictive effect of heartburn and indigestion and risk of upper gastro-intestinal malignancy}

Further to our recent publication of two papers in the BJGP, 1,2 we have been asked to evaluate specifically whether dyspepsia is a significant independent predictor of upper gastro-intestinal malignancy lin other words, gastro-oesophageal and pancreatic malignancyl and to consider adding it to the models. These symptoms (heartburn or indigestion) were not included in the original analysis that had focused on more traditional alarm symptoms. We, therefore, undertook an analysis based on the original derivation cohort from the published studies and identified patients with new onset of (a) heartburn or (b) indigestion lother than where heartburn is explicitly 